\title{
Mice Lacking Epithelial I- $\kappa$ B Kinase are Protected from Lipopolysaccharide and Cigarette Smoke Extract Induced Inflammation
}

David Lamb ${ }^{1 *}$, Nicole Parker ${ }^{1}$, Kristina Ulrich ${ }^{1}$, Gareth Jones ${ }^{2}$, Coralie Afeldorfer ${ }^{2}$, Manolis Pasparakis ${ }^{3}$, Steven Evans ${ }^{1}$, and lain Kilty ${ }^{1}$

${ }^{1}$ Allergy and Respiratory Research Unit, Pfizer Research Laboratories, UK

${ }^{2}$ Drug Safety Research and Development, Pfizer Research Laboratories, UK

IInstitute for Genetics, Zülpicher Strasse 47a, D-50674 Cologne, Germany

\section{Abstract}

Background: IKK-2 activity is essential for cytokine mediated NFKB activation and subsequent expression of a wide variety of inflammatory genes. To investigate the role of IKK-2 signalling in lung epithelium we have developed a knock out mouse in which we have specifically deleted the IKK-2 gene in lung epithelial cells.

Materials and Methods: IKK-2 KO mice and littermate control animals were challenged with either nebulised Lipopolysaccharide (LPS) or with Cigarette Smoke Extract (CSE). Cytokines and inflammatory cells were assessed in Bronchoalveolar Lavage Fluid (BALF) and tissue inflammatory cells, markers of apoptosis and general pathology assessed histologically.

Results: BALF neutrophils were reduced by $63 \%$ at 4 hours and $67 \%$ at 8 hours following LPS challenge in the IKK-2 KO animals $(P<0.001)$. Immunocytochemical analysis showed no difference in neutrophil numbers within pulmonary tissue between the groups or any evidence of increased apoptosis. BALF neutrophils were also reduced below control values in the IKK-2 KO mice in response to CSE compared to littermates animals $(P<0.005)$.

Conclusion: Mice lacking IKK-2 in the pulmonary epithelium recruit fewer neutrophils into the airways in response to both LPS and CSE challenge, suggesting that the epithelium participates in airway inflammatory neutrophil recruitment in response to inflammatory challenge.

Keywords: IKK-2; Mice; Knockout; Lipopolysaccharide; Cigarette smoke; Pulmonary inflammation

Abbreviations: BALF: Bronchoaveolar Lavage Fluid; COPD: Chronic Obstructive Pulmonary Disease; CSE: Cigarette Smoke Extract; FID: Flame Ionisation Detection; GC: Gas Chromatography; GM-CSF: Granulocyte Macrophage Colony Stimulating Factor; ICAM: Intercellular Adhesion Molecule; IFN: Interferon; IKK-2: I- $\kappa B$ Kinase; IL: Interleukin; KC: Keratinocyte-derived Cytokine; LPS: Lipopolysaccharide; MCP: Monocyte Chemotactic Peptide; MS: Mass Spectrometry; NEMO: NF- $\kappa B$ Essential Modulator; PBS: Phosphate Bufferede Saline; RT-PCR: Reverse Transcription Polymerase Chain Reaction; rtTA: Reverse Tetracyclineresponsive Transactivator; TNF: Tumour Necrosis Factor; WT: Wild Type

\section{Background}

The I- $\mathrm{BB}$ kinase (IKK) complex is a $\sim 900-\mathrm{kDa}$ multiprotein complex that is responsible for signal-dependent phosphorylation of I $\kappa$ B. It contains two catalytic subunits I- $\kappa B$ kinase- $\alpha$ and I- $\kappa B$ kinase $-\beta$ (IKK- $\beta$; IKK-2), and an essential regulatory subunit, NF- $\kappa B$ Essential Modulator (NEMO) [1-3]. Gene targeting experiments have established that activation of IKK-2 leads to a rapid and transient translocation of active nuclear factor- $\kappa \mathrm{B}(\mathrm{NF}-\kappa \mathrm{B}$; RelA/p65-p50) to the nucleus and transcription of pro-inflammatory genes. Cells lacking IKK-2 display almost no p65/p50 nuclear binding in response to pro-inflammatory mediators such as tumour necrosis factor- $\alpha$ (TNF- $\alpha$ ) or interleukin-1 (IL-1) $[4,5]$.

Respiratory virus infection, allergens, bacteria, cigarette smoke and proinflammatory cytokines that have all been implicated in the inflammatory response observed in asthma and COPD, can activate nuclear factor- $\kappa \mathrm{B}(\mathrm{NF}-\kappa \mathrm{B})$ [6]. Prednisolone has been shown to inhibit $\mathrm{NF}-\kappa \mathrm{B}$ activation in alveolar macrophages from patients with asthma with a corresponding decrease in the release of the inflammatory mediators, interleukin (IL)-8, TNFa and granulate-macrophage colonystimulating factor (GM-CSF) [7]. Expression of the adhesion molecule intercellular adhesion molecule-1 (ICAM-1) on epithelial cells is highly dependent upon the NF- $\kappa B$ pathway [8]. The NF- $\kappa B$ pathway has also been implicated in the control of neutrophil chemotaxis and apoptosis, as well as T-cell, macrophage and epithelial cell function $[9,10]$. Furthermore, NF- $\kappa \mathrm{B}$ inhibitors can regulate airway smooth muscle proliferation and various other factors involved in airway remodelling in an animal model of asthma [11].

In clinical studies, persistent activation of $\mathrm{NF \kappa B}$ and inhibition of IKK-2 have been reported in patients with uncontrolled asthma $[12,13]$. NF- $\kappa B$ has also been found to be activated in sputum cells from patients with stable COPD, and further increases in activation are observed during exacerbation [14]. Furthermore, neutrophils isolated from the sputum of COPD patients and smokers show elevated NF$\mathrm{\kappa B}$ compared with those from non-smokers, which was associated with impaired apoptosis [15].

Neutrophilic lung inflammation has frequently been modelled pre-clinically by exposure to Lipoploysaccharide (LPS) or cigarette smoke [16]. Cigarette smoke exposure is usually performed either by a 'nose only' or by a 'whole body' methodology, but neither the type of cigarettes, the number of cigarettes/day nor the duration of the exposure is standardized. The obvious advantage of these models is that the whole cigarette smoke stimulus bears a direct resemblance to smoke

*Corresponding author: David Lamb, Allergy and Respiratory Research Unit, Pfizer Research Laboratories, Pfizer (UK) Ltd, Ramsgate Road, Sandwich, Kent CT13 9NJ, UK, E-mail: david.lamb@boehringer-ingelheim.com

Received January 30, 2012; Accepted February 20, 2013; Published February 25, 2013

Citation: Lamb D, Parker N, Ulrich K, Jones G, Afeldorfer C, et al. (2013) Mice Lacking Epithelial I-KB Kinase are Protected from Lipopolysaccharide and Cigarette Smoke Extract Induced Inflammation. J Pulmon Resp Med 3: 142. doi:10.4172/2161-105X. 1000142

Copyright: $\odot 2013$ Lamb D, et al. This is an open-access article distributed under the terms of the Creative Commons Attribution License, which permits unrestricted use, distribution, and reproduction in any medium, provided the original author and source are credited. 
exposure in humans. However, whole body exposure lacks the specific organ targeting associated with cigarette smoking and requires the use of complicated and expensive smoke exposure apparatus. One alternative is to generate an aqueous extract of cigarette smoke that enables dosing specifically to the lung area. We have developed a 5-day intranasal challenge mouse model using aqueous extract of cigarette smoke based upon data from a recent study that showed 40 day challenge increased lung neutrophil and lymphocyte count, KC, TNF- $\alpha$ and mucin [17]. CSE exposure in mice elicits airway neutrophilia, upregulation of muc5AC, and is sensitive to both PDE4 and p38 inhibition, but not to treatment with steroids [18]. It therefore bears many of the hallmarks of traditional cigarette exposure models.

The aim of this study was to assess the contribution of IKK- $\beta$ to pulmonary inflammation elicited by either LPS or CSE in mice specifically lacking IKK- $\beta$ in the lung epithelium.

\section{Materials and Methods}

\section{Chemicals}

Research Cigarettes (2R4F) were purchased from the Tobacco Research Institute (University of Kentucky, Kentucky, USA). All other regents were purchased from Sigma unless otherwise stated.

\section{Animals}

The gene encoding IKK-2 was selectively deleted in airway epithelial cells by using the Cre/loxP procedure in mice containing IKK-2 flanking loxP sites as described previously [19]. Briefly, floxed IKK-2 mice were mated to SP-C/rtTA mice that express two transgenes, one that expresses the reverse tetracyclineresponsive transactivator (rtTA) under control of the human SP-C promoter, and the second that expresses Cre under control of the tet-operator. These mice were back-crossed onto the C57BL/6 background for 10 generations. The SP-C promoter directs gene expression exclusively to the pulmonary epithelium. When doxycycline is administered to pregnant dams, IKK2 is deleted in airway epithelium in progeny that expresses both of the transgenes and that contains the floxed IKK-2 gene.

Mice were housed and handled according to Home Office legislation and subject to local ethical review and regulations. Food and water were permitted ad libitum.

\section{In situ hybridisation}

Paraffin-embedded tissue was cut, deparaffinized, rehydrated and acetylated. Sections were then overlaid with the hybridization solution containing ${ }^{35}$ S-labelled antisense or, for control, sense probes. Slides were then dipped into Kodak NTB-2 solution, exposed for autoradiography, counterstained and microscopically evaluated. RNase protection assays as were performed as described previously [20]. For polymerase chain reaction with reverse transcription (RT-PCR) analysis the following primers were used: mouse IKK-2, 5'-CTGAAGCAGCTAT GGCAACT-3' and 5'-GGATGCTCTCATCTGGACAG-3'; mouse actin, 5'-TAAAACGC AGCTCAGTAACAGTCCG-3' and 5'-TGGAATCCTGTGGCATCCATGAAAC-3'.

\section{LPS Administration}

Animals were placed into a 45 litre exposure chamber. Aerosols were generated using a Pulmi-Sonic nebuliser (DeVilbis) containing $10 \mathrm{ml} \mathrm{of} 1 \mathrm{mg} / \mathrm{ml}$ LPS (Escherichia coli, serotype 0111:B4) dissolved in saline that had been pre-warmed to $37^{\circ} \mathrm{C}$. The nebuliser was switched on for $15 \mathrm{~min}$ and the resulting aerosols were pumped into the exposure chamber by a small animal ventilator (Harvard; tidal volume $5 \mathrm{ml}$, rate 160 strokes $/ \mathrm{min}$ ). The nebuliser was connected to the exposure chamber with the inlet at the top, such that the mist entered at the top and descended over the animals. After 15 minutes the ventilator and nebuliser were turned off and the animals were kept in the chamber to breathe the mist for a further $15 \mathrm{~min}$.

\section{CSE Preparation}

CSE was prepared daily in a custom designed smoking apparatus that consisted of 2 compartments. A lighted cigarette was placed within a glass "smoking chamber" from which side-stream smoke could be evacuated through an activated carbon filter. Mainstream smoke was withdrawn from the cigarette under negative pressure from a peristaltic pump and passed through Dulbeccos phosphate buffered saline w/o calcium or magnesium (PBS) within a glass "collection chamber" and finally evacuated through a second activated carbon filter. Cigarettes were smoked to within $3 \mathrm{~mm}$ of the cigarette filter, with an average burn time of 7 minutes, before being extinguished. Smoke from 3 cigarettes was drawn through $3 \mathrm{ml}$ of PBS.

Cigarette smoke extract was extracted into an equal volume of dichloromethane and the soluble content analysed by Gas Chromatography (GC) coupled with Flame Ionisation Detection (FID) and Mass Spectroscopy (MS). Five peaks were consistently identified within CSE by GC-FID, the second most abundant being identified by GC-MS as nicotine. Additionally, the spectrophotometric absorption of each preparation was measured and recorded to ensure consistency.

\section{CSE Administration}

Mice were placed in an anaesthetic chamber and exposed to $2.5 \%$ isoflurane in $100 \% \mathrm{O}_{2}$. Intranasal instillation was performed by scruffing the mouse and pipetting $50 \mu \mathrm{l}$ of CSE onto the nostrils of the animal as it was held in a vertical position. The anaesthetized animal inhaled CSE spontaneously before being placed back in the cage in an inclined position for recovery.

\section{Bronchoalveolar lavage (BALF) and cell count}

Mice were killed by $0.1 \mathrm{ml}$ i.p. PentoJect ${ }^{\circ}$ anesthesia overdose. The thoracic cavity was opened and blood withdrawn by cardiac puncture. The trachea was cannulated with a 20GA Insyte I.V. catheter (Becton Dickinson, Oxford, UK) and the lungs lavaged with $4 \times 0.5 \mathrm{ml}$ PBS containing $10 \mathrm{mM}$ EDTA. Lavages from individual animals were pooled and yielded a consistent return of approximately $1.9 \mathrm{ml}$ that contained $90 \%$ of available cells (data not shown). BALF was diluted 1:1 in trypan blue and cell density counted in a haemocytometer. Cytospins were prepared on microscope slides (Thermo Shandon, Runcorn, UK), air dried and stained with DiffQuik (Dade Behring, Milton Keynes, UK). Differential cell counts were performed manually using a light microscope counting at least 300 cells from each slide. The remaining BALF sample was centrifuged and the cell-free fraction frozen at $-20^{\circ} \mathrm{C}$ for cytokine analysis.

\section{Cytokine assays}

Murine TNF- $\alpha$, KC, IL-1 $\beta$, IL-6, IL-10, IL-12 and IFN- $\gamma$ were measured in serum and lavage samples using a pro-inflammatory multiplex chemiluminescent immunoassay kit (Meso Scale Discovery, Gaithersburg, MD) according to instructions.

\section{Histology and immunostaining}

Lungs and trachea were excised and inflation fixed with $10 \%$ Neutral buffered formalin. All lung samples were fixed for 24 hours before being processed into paraffin wax overnight (VIP, Sakura 
Citation: Lamb D, Parker N, Ulrich K, Jones G, Afeldorfer C, et al. (2013) Mice Lacking Epithelial I-KB Kinase are Protected from Lipopolysaccharide and Cigarette Smoke Extract Induced Inflammation. J Pulmon Resp Med 3: 142. doi:10.4172/2161-105X. 1000142

Page 3 of 6

Finetek U.S.A., Inc) and embedded into paraffin wax blocks. $4 \mu \mathrm{m}$ thick sections were cut and floated out onto glass slides, before being dried overnight at $37^{\circ} \mathrm{C}$. Sections were stained immunohistochemically for RelA (mouse anti RelA (R\&D Systems MAB5078)), visualised with 3,3'-diaminobenzidine and counterstained with haematoxylin.

\section{Statistical Analyses}

Analysis of variance was used to determine statistical significance unless stated. Analysis was performed using LabStats, a Microsoft Excel add-in created by the Biostatistics and Reporting Group at Sandwich Laboratories in collaboration with Tessella Support Services plc (Abingdon, Oxon, UK).

\section{Results}

\section{IKK-2 KO mice}

In situ hybridisation in lung tissue from mice that express the raTA and Cre transgenes and the floxed IKK-2 gene but did not receive doxycycline in utero showed IKK-2 mRNA in the epithelium, whereas IKK-2 KO mice that did receive doxycycline in utero demonstrated an absence of epithelial IKK-2 mRNA (Figure 1a-d). Southern blot analysis confirmed a reduction in lung IKK-2 mRNA from the same animals (data not shown). Knockout of IKK-2 throughout the lung epithelium did not cause any specific pathology as compared to WT controls in unchallenged animals (data not shown).

\section{Pulmonary inflammation in IKK-2 KO mice following LPS exposure}

Following inhaled LPS challenge, pulmonary neutrophils in littermate control mice were significantly increased in BALF at 4,8 and 24 hours post-exposure, peaking at the 8 hour time point (Figure 2). IKK-2 KO mice exhibited a significant reduction $(63 \%$ and $67 \%$ less) at the 4 hour and 8 hour time points respectively, compared to littermate control animals $(\mathrm{P}<0.05)$. It is possible that the lower levels of airway neutrophils in the IKK-2 KO mice may be as a result of tissue accumulation of cells. However, imunocytochemical analysis showed no difference in neutrophil numbers within pulmonary tissue between

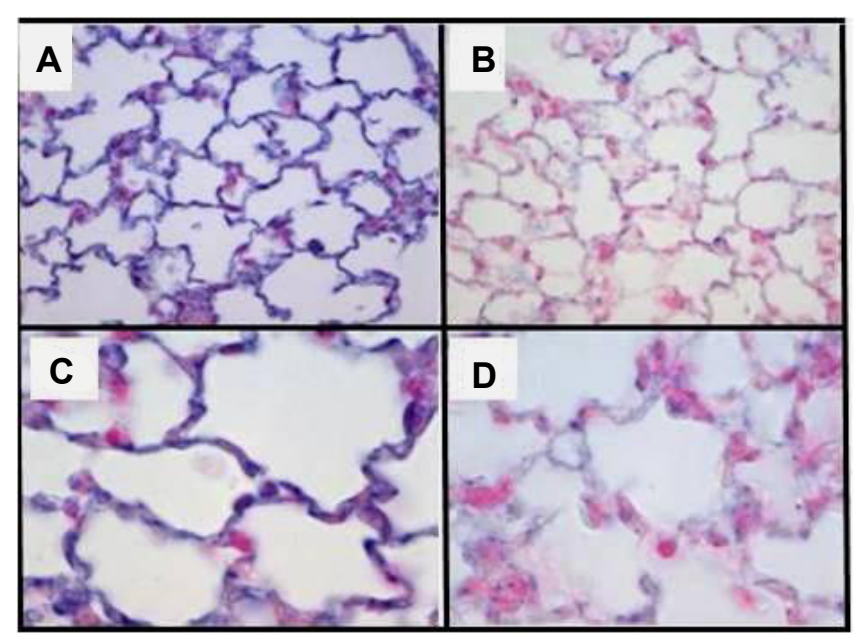

Lung sections from mice expressing raTA and Cre transgenes and the floxed IKK-2 gene that did not receive ( $a$ and $c$ ) or that received ( $b$ and d) doxycycline in utero were probed by in situ hybridisation for IKK-2 mRNA. Sections were counterstained with haematoxylin and eosin. Images of $\times 20(a$ and $b)$ and $\times 40$ (c and d) magnification are shown.

Figure 1: IKK-2 KO Mouse in situ hybridization.

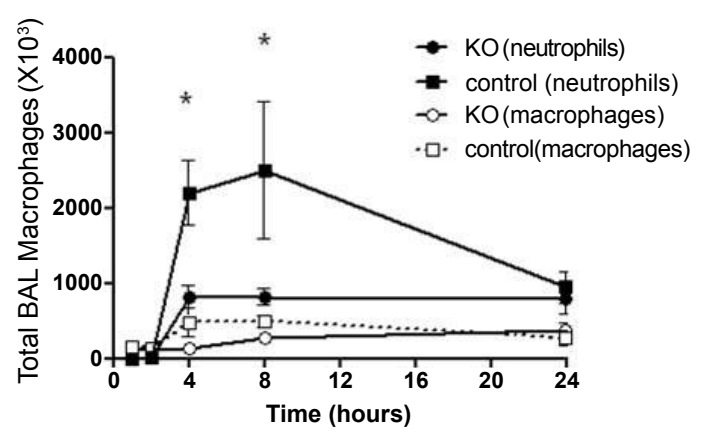

Mice were challenged with aerosolised LPS and killed at various time points post-challenge. Lungs were lavaged and neutrophils counted. Values are geometric mean \pm SEM of 4 animals. ${ }^{*} \mathrm{P}<0.05$ (vs littermate control animals)

Figure 2: BALF neutrophil counts post-LPS challenge.
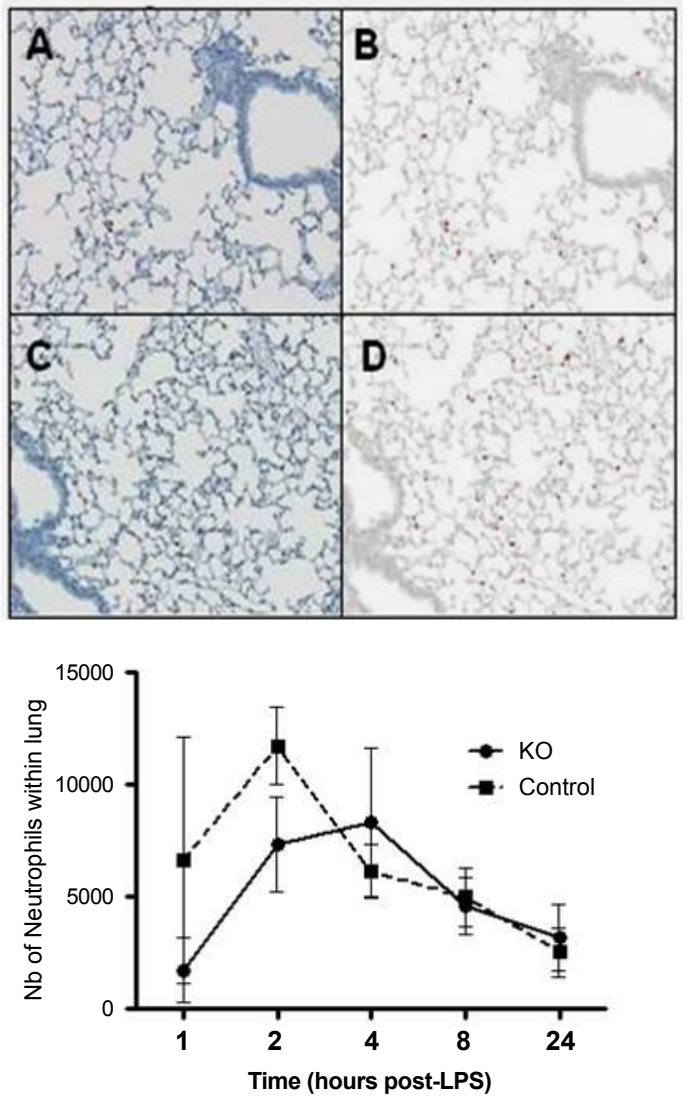

Lung sections from IKK-2 (A) and littermate controls (B) four hours after exposure to LPS were stained for myeloperoxidase and neutrophil density quantified by Definiens image analysis software (C and D). Images of $\times 20$ magnification are shown. The geometric mean neutrophil count $( \pm$ SEM) for both groups at each time point is shown (E)

Figure 3: Immunocytochemical staining and quantification of tissue neutrophils.

the groups at any time point (Figure 3) suggesting that the observed reduction in neutrophil count was not due to inhibition of migration between capillary and airspace with subsequent retention within the pulmonary tissue. 
Citation: Lamb D, Parker N, Ulrich K, Jones G, Afeldorfer C, et al. (2013) Mice Lacking Epithelial I-KB Kinase are Protected from Lipopolysaccharide and Cigarette Smoke Extract Induced Inflammation. J Pulmon Resp Med 3: 142. doi:10.4172/2161-105X. 1000142

Page 4 of 6

There was a significantly lower level of the neutrophil chemokine $\mathrm{KC}$ in the BALF of IKK-2 KO animals compared with controls 1 hour post-LPS challenge, but not at subsequent time points (Table
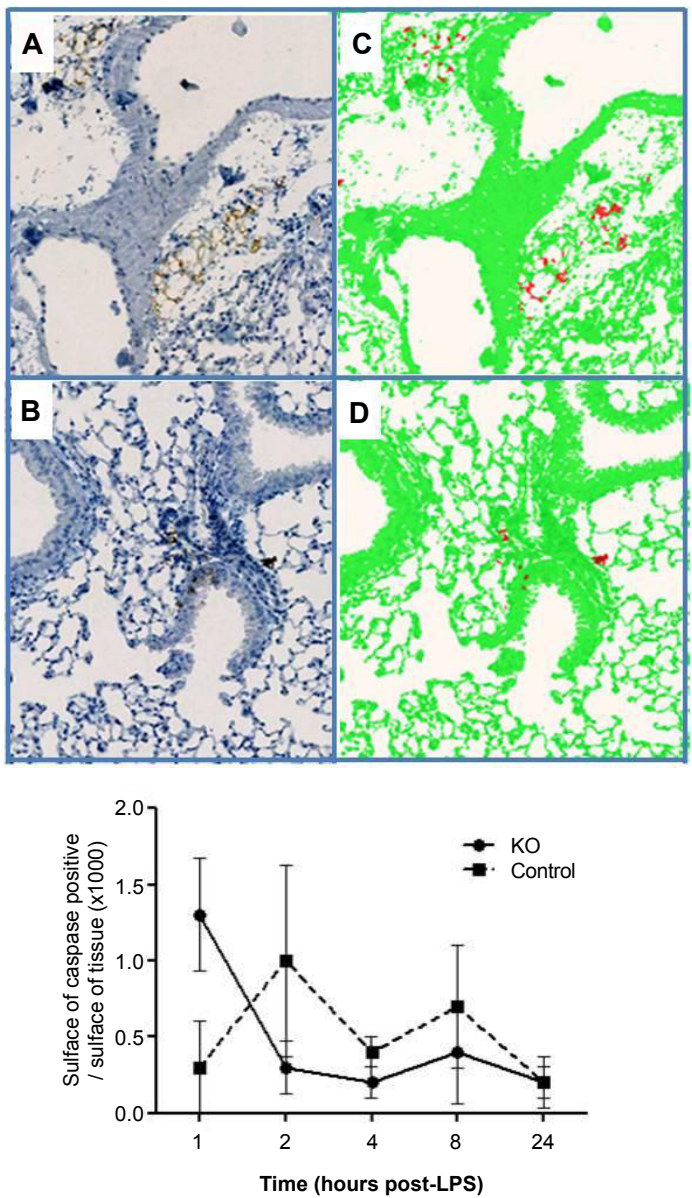

Lung sections from IKK-2 (A) and littermate controls (B) twenty four hours after exposure to LPS were stained for active caspase-3 and area positively stained quantified by Definiens image analysis software (C and D). Images of $\times 20$ magnification are shown. The geometric mean of the ratio of positively: negatively stained areas $( \pm$ SEM) for both groups at each time point is shown $(E)$ Figure 4: Immunocytochemical staining and quantification of active caspase-3.
1). Interestingly, in the $\mathrm{KO}$ animals, increased levels of TNF- $\alpha$ were observed at the 2 hour time point, and increased levels of IL- 6 and IL10 observed at the 4 hour time point compared to control animals.

\section{Caspase-3 activation in IKK-2 KO mice following LPS exposure}

$\mathrm{NF}-\mathrm{kB}$ has a complex role in the regulation of apoptosis and activation of p65/p50 has been associated with both anti- and proapoptotic effects $[21,22]$. To investigate whether KO of IKK-2 in lung epithelium caused an increased rate of apoptosis on LPS challenge, activity of caspase 3 was assessed. Active caspase- 3 staining in the epithelium was uniformly low in all study groups and the area staining positively for active caspase- 3 was similar in both IKK-2 KO mice and the littermate control animals, suggesting that there was no specific effects on apoptosis that may complicate interpretation of inflammatory endpoints (Figure 4).

\section{Pulmonary inflammation in IKK-2 KO mice following CSE exposure}

To assess the role of IKK-2 in another pulmonary inflammation model, IKK-2 KO mice and their littermate controls were exposed to 4 consecutive days of CSE. Following CSE challenge, neutrophils were significantly elevated in the littermate control animals compared with saline treatment. BALF neutrophils were reduced to below control values in the IKK-2 KO mice in response to CSE compared to both littermates and WT animals (Table 2; $\mathrm{P}<0.005$ ). BALF macrophages numbers were consistent between CSE-treated and control animals, and IKK-2 deletion made no impact on either group. Cytokine concentrations in BALF were below the limit of detection of the assay.

\section{Discussion}

The lung epithelium provides the initial line of defence from invading pathogens and noxious chemicals in the lung. In addition to barrier function these cells are responsible for mediating the inflammatory response to a range of stimuli and an increased understanding of the key inflammatory pathways activated in these cells may provide novel therapeutic targets for the treatment of lung inflammation. Our results presented here show that epithelial-specific deletion of IKK-2 resulted in a reduction in pulmonary inflammation elicited by either LPS or CSE. These effects did not appear to be associated with either neutrophil accumulation within lung tissue, or epithelial cell apoptosis. Thus, IKK-2 deletion in the pulmonary epithelium and subsequent

\begin{tabular}{|c|c|c|c|c|c|c|}
\hline & \multirow[b]{2}{*}{ Time } & \multicolumn{5}{|c|}{ BALF Cytokine Concentration (pg/ml) } \\
\hline & & 1 hour & 2 hour & 4 hour & 8 hour & 24 hour \\
\hline \multirow[t]{2}{*}{ IL-6 } & $\mathrm{IKK}-2 \mathrm{KO}$ & $519 \pm 37$ & $2316 \pm 325$ & $3698 \pm 728^{* *}$ & $1500 \pm 437$ & $28 \pm 16$ \\
\hline & Control & $1005 \pm 215$ & $1532 \pm 216$ & $1984 \pm 216$ & $859 \pm 142$ & $16 \pm 14$ \\
\hline \multirow[t]{2}{*}{$\mathrm{IL}-10$} & IKK-2 KO & $55 \pm 10$ & $142 \pm 18$ & $138 \pm 24^{*}$ & $36 \pm 20$ & $8 \pm 4$ \\
\hline & Control & $124 \pm 16$ & $133 \pm 11$ & $84 \pm 19$ & $28 \pm 10$ & $18 \pm 6$ \\
\hline \multirow[t]{2}{*}{$\mathrm{IL}-12$} & $\mathrm{IKK}-2 \mathrm{KO}$ & $0 \pm 0$ & $159 \pm 44$ & $223 \pm 33$ & $46 \pm 41$ & $0 \pm 0$ \\
\hline & Control & $99 \pm 16$ & $244 \pm 15$ & $317 \pm 170$ & $38 \pm 12$ & $29 \pm 20$ \\
\hline \multirow[t]{2}{*}{$\mathrm{KC}$} & $\mathrm{IKK}-2 \mathrm{KO}$ & $670 \pm 88^{\star *}$ & $1026 \pm 185$ & $731 \pm 86$ & $85 \pm 26$ & $17 \pm 9$ \\
\hline & Control & $1204 \pm 126$ & $1275 \pm 305$ & $912 \pm 214$ & $149 \pm 13$ & $68 \pm 13$ \\
\hline \multirow[t]{2}{*}{ TNF- $\alpha$} & $\mathrm{IKK}-2 \mathrm{KO}$ & $1433 \pm 127$ & $1340 \pm 369^{*}$ & $547 \pm 185$ & $53 \pm 10$ & $12 \pm 2$ \\
\hline & Control & $1249 \pm 186$ & $720 \pm 364$ & $360 \pm 114$ & $63 \pm 19$ & $12 \pm 3$ \\
\hline
\end{tabular}

Mice were challenged with aerosolised LPS and killed at various time points post-challenge. Lungs were lavaged and cytokine levels in BALF assayed. Values are geometric mean \pm SEM of 4 animals. ${ }^{*} \mathrm{P}<0.05$, ${ }^{* *} \mathrm{P}<0.005$ (knockout animals vs controls)

Table 1: BALF cytokine content post-LPS challenge. 
Citation: Lamb D, Parker N, Ulrich K, Jones G, Afeldorfer C, et al. (2013) Mice Lacking Epithelial I-KB Kinase are Protected from Lipopolysaccharide and Cigarette Smoke Extract Induced Inflammation. J Pulmon Resp Med 3: 142. doi:10.4172/2161-105X. 1000142

Page 5 of 6

\begin{tabular}{|l|c|c|c|c|}
\hline \multirow{2}{*}{} & \multicolumn{2}{|c|}{$\begin{array}{r}\text { BALF Neutrophil count } \\
\left(\times 10^{3} \text { cells }\right)\end{array}$} & \multicolumn{2}{c|}{$\begin{array}{r}\text { BALF Macrophage Count } \\
\left(\times 10^{3} \text { cells }\right)\end{array}$} \\
\hline Treatment & saline & CSE & saline & CSE \\
\hline IKK-2 KO & $561 \pm 238$ & $67 \pm 54^{* *}$ & $125 \pm 24$ & $111 \pm 23$ \\
\hline Control & $871 \pm 483$ & $6744 \pm 3754$ & $142 \pm 34$ & $171 \pm 18$ \\
\hline
\end{tabular}

Mice were challenged with CSE for 4 consecutive days. Lungs were lavaged and neutrophils counted. Values are geometric mean \pm SEM of 4 animals. ${ }^{* *} \mathrm{P}<0.005$ vs control animals.

Table 2: BALF neutrophil counts post-CSE challenge.

loss of NF- $\mathrm{\kappa B}$ activation attenuated pulmonary inflammation in two independent mouse models. The less pronounced inflammatory neutrophilic response to LPS was a maximum of $67 \%$ less in the knockout animals compared with their littermate controls 8 hours post-challenge. These findings are consistent with those reported by Poynter et al. [23] who showed that epithelial-specific deletion of IKK2 in mice attenuated neutrophilic influx in response to intranasal LPS. This would suggest that epithelial cells are not wholly responsible for LPS-mediated inflammatory cell recruitment. Alveolar macrophages produce the neutrophil chemokine IL-8 in response to LPS [24] and are believed to play a role in neutrophil recruitment in COPD [25], so it is perhaps not surprising that epithelial-specific deletion of IKK-2 does not entirely ablate LPS-elicited neutrophil influx. These findings are consistent with a previous study that found epithelial-specific expression of I- $\kappa \mathrm{B} \alpha$ super-repressor in mice resulted in attenuation of LPS-elicited airway neutrophilia [26]. The role of NF- $\kappa B$ in pulmonary inflammation is not confined to LPS-elicited inflammation, and there are reports of IKK-2 inhibitors attenuating OVA- [27], bleomycin- [28], and IL-13 [29] induced pulmonary inflammation in mice. Furthermore, overexpression of IKK-2 in airway epithelium results in spontaneous elevations in airway neutrophilia [30].

Whilst IKK-2 deletion resulted in a reduction in the neutrophil chemokine $\mathrm{KC}$ and the pro-inflammatory cytokine IL-12 following LPS challenge, there were concomitant increases in the pro-inflammatory cytokines TNF- $\alpha$ and IL- 6 in the knockout animals at the 2 and 4 hour time points respectively compared with their littermates. Both TNF- $\alpha$ and IL- 6 are synthesised at high levels by activated macrophages, so the absence of a reduction in these cytokines may indicate that airway macrophages are the predominant source of these cytokines following LPS challenge. Whilst the reduction of the pro-inflammatory cytokine IL-12 and increase in the inflammation-suppressing IL-10 cytokine suggest that knocking out epithelial IKK-2 has a net anti-inflammatory effect, the fact that these cytokines are predominantly secreted by macrophages and monocytes respectively, suggests a complex interplay between the epithelium and other cell types.

In contrast to the partial inhibition of LPS-elicited neutrophilia by epithelial-specific deletion of IKK-2, cigarette smoke extract-elicited neutrophilia was completely ablated by deletion of IKK-2, suggesting that perhaps the epithelium plays a more central role in neutrophil recruitment in this model. A recent study demonstrates that the IKK2 inhibitor, IMD-0354, attenuates cigarette smoke-mediated influx of neutrophils into the airways, with a concomitant reduction in the cytokines MCP-1 and IP-10 [31]. The apparent differences between the magnitude of effect observed in the currently reported and above noted study may reflect the differences in model (cigarette smoke extract versus cigarette smoke), anatomical IKK-2 inhibition (epithelial versus total) or magnitude of inhibition (deletion versus pharmacological intervention). Nevertheless, the findings are broadly similar between the two studies. Interestingly, in the same study, deletion of the p50 NF$\kappa \mathrm{B}$ sub-unit augmented the cellular and cytokine pro-inflammatory responses to cigarette smoke and increased airspace enlargement, suggesting a regulatory role for p50 in cigarette smoke-mediated inflammation [31].

As activation of NF- $\mathrm{kB}$ is associated with protection of epithelial cells from apoptosis, we investigated whether IKK-2 KO and inflammatory stimulation increased apoptosis in the lung. Using Caspase 3 activity as a surrogate for cellular apoptosis we have shown no activation of this pathway in response to deletion of IKK-2. Combining these data with the anti-inflammatory effect observed in the IKK-2 epithelial KO mice; this would provide encouragement that lung delivery of an IKK-2 inhibitor targeted to the epithelium may be an effective and safe therapy.

In conclusion, specific deletion of IKK-2 from lung epithelium ameliorates neutrophil influx in both LPS- and cigarette smoke-induced pulmonary inflammation.

\section{Authors Contributions}

MP generated the mouse line. DL, IK and SM participated in the design of the study and. DL, NP and KU performed the animal experiments. GJ and CA performed the image analysis. DL, MP, IK and SM helped to draft the manuscript.

\section{References}

1. DiDonato JA, Hayakawa M, Rothwarf DM, Zandi E, Karin M (1997) A cytokineresponsive IkappaB kinase that activates the transcription factor NF-kappaB. Nature 388: 548-554

2. Zandi E, Rothwarf DM, Delhase M, Hayakawa M, Karin M (1997) The IkappaB kinase complex (IKK) contains two kinase subunits, IKKalpha and IKKbeta, necessary for IkappaB phosphorylation and NF-kappaB activation. Cell 91 243-252.

3. Woronicz JD, Gao X, Cao Z, Rothe M, Goeddel DV (1997) IkappaB kinasebeta: NF-kappaB activation and complex formation with lkappaB kinase-alpha and NIK. Science 278: 866-869.

4. Mercurio F, Zhu H, Murray BW, Shevchenko A, Bennett BL, et al. (1997) IKK1 and IKK-2: cytokine-activated IkappaB kinases essential for NF-kappaB activation. Science 278: 860-866.

5. Li ZW, Chu W, Hu Y, Delhase M, Deerinck T, et al. (1999) The IKKbeta subunit of IkappaB kinase (IKK) is essential for nuclear factor kappaB activation and prevention of apoptosis. J Exp Med 189: 1839-1845.

6. Bonizzi G, Karin M (2004) The two NF-kappaB activation pathways and thei role in innate and adaptive immunity. Trends Immunol 25: 280-288.

7. Cosío BG, Mann B, Ito K, Jazrawi E, Barnes PJ, et al. (2004) Histone acetylase and deacetylase activity in alveolar macrophages and blood mononocytes in asthma. Am J Respir Crit Care Med 170: 141-147.

8. Holden NS, Catley MC, Cambridge LM, Barnes PJ, Newton R (2004) ICAM-1 expression is highly NF-kappaB-dependent in A549 cells. No role for ERK and p38 MAPK. Eur J Biochem 271: 785-791.

9. Kumar S, Boehm J, Lee JC (2003) p38 MAP kinases: key signalling molecules as therapeutic targets for inflammatory diseases. Nat Rev Drug Discov 2: 717 726

10. Bryan SA, Leckie MJ, Hansel TT, Barnes PJ (2000) Novel therapy for asthma Expert Opin Investig Drugs 9: 25-42.

11. Eynott PR, Nath P, Leung SY, Adcock IM, Bennett BL, et al. (2003) Allergeninduced inflammation and airway epithelial and smooth muscle cell proliferation role of Jun N-terminal kinase. Br J Pharmacol 140: 1373-1380.

12. Hart LA, Krishnan VL, Adcock IM, Barnes PJ, Chung KF (1998) Activation and localization of transcription factor, nuclear factor-kappaB, in asthma. Am J Respir Crit Care Med 158: 1585-1592.

13. Gagliardo R, Chanez P, Mathieu M, Bruno A, Costanzo G, et al. (2003) Persistent activation of nuclear factor-kappaB signaling pathway in severe uncontrolled asthma. Am J Respir Crit Care Med 168: 1190-1198.

14. Caramori G, Romagnoli M, Casolari P, Bellettato C, Casoni G, et al. (2003) Nuclear localisation of p65 in sputum macrophages but not in sputum neutrophils during COPD exacerbations. Thorax 58: 348-351.

15. Brown V, Elborn JS, Bradley J, Ennis M (2009) Dysregulated apoptosis and NFkappaB expression in COPD subjects. Respir Res 10: 24. 
Citation: Lamb D, Parker N, Ulrich K, Jones G, Afeldorfer C, et al. (2013) Mice Lacking Epithelial I-KB Kinase are Protected from Lipopolysaccharide and Cigarette Smoke Extract Induced Inflammation. J Pulmon Resp Med 3: 142. doi:10.4172/2161-105X. 1000142

16. Brusselle GG, Bracke KR, Maes T, D’hulst AI, Moerloose KB, et al. (2006) Murine models of COPD. Pulm Pharmacol Ther 19: 155-165.

17. Miller LM, Foster WM, Dambach DM, Doebler D, McKinnon M, et al. (2002) A murine model of cigarette smoke-induced pulmonary inflammation using intranasally administered smoke-conditioned medium. Exp Lung Res 28: 435455.

18. Lamb D, Ulrich K, Fancy SA, Perkins G, Douglas G, et al. (2007) Characterisation of a sub-acute mouse model of cigarette smoke extractinduced lung inflammation. Eur Res J 40: 625

19. Broide DH, Lawrence T, Doherty T, Cho JY, Miller M, et al. (2005) Allergeninduced peribronchial fibrosis and mucus production mediated by lkappaB kinase beta-dependent genes in airway epithelium. Proc Natl Acad Sci U S A 102: $17723-17728$

20. Werner S, Weinberg W, Liao X, Peters KG, Blessing M, et al. (1993) Targeted expression of a dominant-negative FGF receptor mutant in the epidermis of transgenic mice reveals a role of FGF in keratinocyte organization and differentiation. EMBO J 12: 2635-2643.

21. Van Antwerp DJ, Martin SJ, Kafri T, Green DR, Verma IM (1996) Suppression of TNF-alpha-induced apoptosis by NF-kappaB. Science 274: 787-789.

22. Ryan KM, Ernst MK, Rice NR, Vousden KH (2000) Role of NF-kappaB in p53mediated programmed cell death. Nature 404: 892-897.

23. Poynter ME, Irvin CG, Janssen-Heininger YM (2003) A prominent role for airway epithelial NF-kappa B activation in lipopolysaccharide-induced airway inflammation. J Immunol 170: 6257-6265.

24. Li SL, Zhang SQ, Qin CP, Chen B, Chen ZT, et al. (2006) Changes in inflammatory cytokines released by pulmonary intravascular macrophages after stimulation with lipopolysaccharide. Zhongguo Wei Zhong Bing Ji Jiu Yi Xue 18: 136-138

25. Murugan V, Peck MJ (2009) Signal transduction pathways linking the activation of alveolar macrophages with the recruitment of neutrophils to lungs in chronic obstructive pulmonary disease. Exp Lung Res 35: 439-485.

26. Poynter ME, Irvin CG, Janssen-Heininger YM (2003) A prominent role fo airway epithelial NF-kappa B activation in lipopolysaccharide-induced airway inflammation. J Immunol 170: 6257-6265.

27. Sugita A, Ogawa H, Azuma M, Muto S, Honjo A, et al. (2009) Antiallergic and anti-inflammatory effects of a novel I kappaB kinase beta inhibitor, IMD-0354, in a mouse model of allergic inflammation. Int Arch Allergy Immunol 148: 186-198.

28. Inayama M, Nishioka Y, Azuma M, Muto S, Aono Y, et al. (2006) A novel IkappaB kinase-beta inhibitor ameliorates bleomycin-induced pulmonary fibrosis in mice. Am J Respir Crit Care Med 173: 1016-1022.

29. Chapoval SP, Al-Garawi A, Lora JM, Strickland I, Ma B, et al. (2007) Inhibition of NF-kappaB activation reduces the tissue effects of transgenic IL-13. J Immuno 179: $7030-7041$

30. Sadikot RT, Han W, Everhart MB, Zoia O, Peebles RS, et al. (2003) Selective I kappa B kinase expression in airway epithelium generates neutrophilic lung inflammation. J Immunol 170: 1091-1098.

31. Rajendrasozhan S, Chung S, Sundar IK, Yao H, Rahman I (2010) Targeted disruption of NF-\{kappa\}B1 (p50) augments cigarette smoke-induced lung inflammation and emphysema in mice: a critical role of p50 in chromatin remodeling. Am J Physiol Lung Cell Mol Physiol 298: L197-209. 